\title{
NOTE ON STYLISTIC USAGE
}

It has been impossible to maintain complete uniformity in the use of Spanish (Castilian) and Catalan words and names in the text of this book. I have tended to keep the names of institutions in their original Catalan (e.g. Generalitat). While some placenames are the same in both languages (e.g. Tarragona), others differ (e.g. Lérida in Castilian, Lleida in Catalan). I have usually opted for the Catalan version. The names of individual Catalans present an intractable problem. For most of the nineteenth century it was common for them to use the Castilian version on public occasions, even when they normally spoke Catalan to each other. Nowadays the Catalan form is the one commonly used in Catalonia itself (e.g. General Joan Prim, and not Juan Prim). I have followed this practice from around 1800 onwards, although with occasional exceptions. For instance, the seventeenth-century rebel leader is always known as Pau Claris and not Pablo Claris, and it would be absurd to use the Castilian version of his name. Names of authors are particularly difficult, since, far into the Romantic movement, their books are likely to be published under Castilian names, and this is how they appear in bibliographies and library catalogues. Thus, the late seventeenth-century merchant and projector, Narciso Feliu de la Peña, tends nowadays to be known by the Catalan version of his name as Narcís Feliu de la Penya, but his treatises were published in Castilian, with his name in Castilian. I have respected this practice up to around 1800, which I have taken as a rough dividing line, although long hesitating between Antonio de Capmany and Antoni de Capmany, the well-known historian and politician whose career straddled the two centuries. My final choice, the Catalan form, is purely arbitrary. I have used the English version 
of names of Spanish monarchs (Philip II and not Felipe II), with the exception of Charles II of Spain, who appears in the text as Carlos II to distinguish him from his contemporary, Charles II of England and Scotland.

It should be noted that dates in the chapter headings are intended to serve as chronological indications of the general period covered by each chapter, and should be regarded as no more than approximate. 


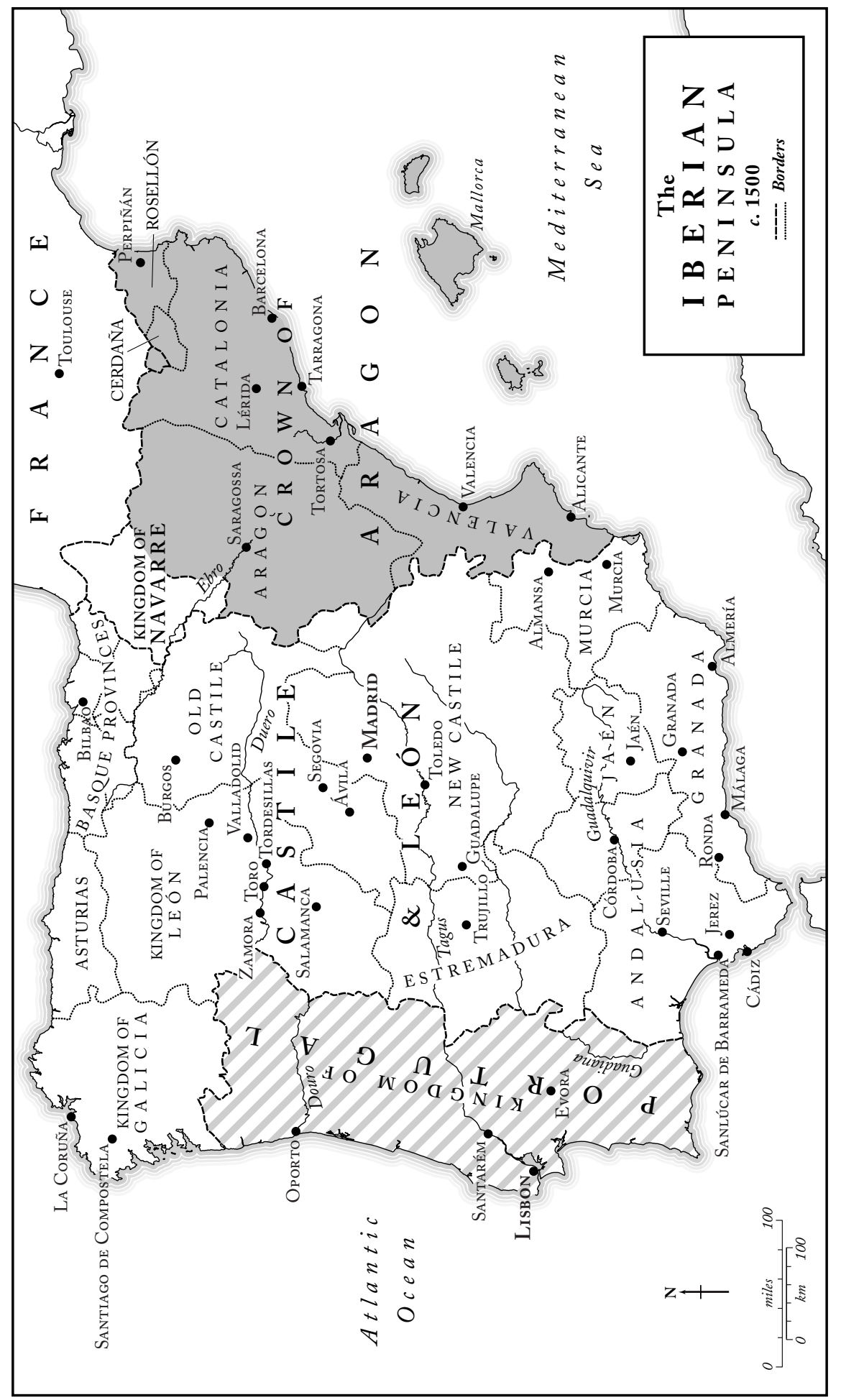

